ISSN 0103-9954

\title{
CRESCIMENTO DE PLANTAS JOVENS DE AÇOITA-CAVALO EM QUATRO DIFERENTES SUBSTRATOS
}

\section{THE GROWTH IN SEEDLINGS OF AÇOITA-CAVALO (Luehea divaricata) IN FOUR DIFFERENT SUBSTRACTS}

Fernanda Grave $^{1}$ Elcí Terezinha Henz Franco ${ }^{2}$ Jardel Pizzatto Pacheco ${ }^{3} \quad$ Sidney Rodrigues Santos ${ }^{3}$

\section{RESUMO}

A espécie Luehea divaricata Mart. \& Zucc., da família Malvaceae, possui madeira de alta qualidade, que tem sido empregada principalmente na confecção de móveis vergados, razão pela qual se encontra atualmente dizimada. A reposição em matas remanescentes bem como a sua utilização em projetos de reflorestamento necessitam da produção de mudas em larga escala. O objetivo deste estudo foi avaliar o crescimento de plântulas de Luehea divaricata obtidas por semente, cultivadas em quatro substratos. Foram colocadas quatro sementes por tubete nos substratos Plant Max ${ }^{\circledR}$, turfa, casca de arroz carbonizada e Mec Plant ${ }^{\circledR}$. Aos 25 dias após a semeadura, foi efetuada a repicagem das mudas dentro de cada tratamento e, aos 50 dias, foi efetuado o desbaste. Avaliaram-se: percentagem de germinação das sementes, massa seca das raízes $(\mathrm{g})$, massa seca da parte aérea $(\mathrm{g})$, diâmetro do colo $(\mathrm{cm})$, altura da parte aérea $(\mathrm{cm})$ e número médio de folhas. O delineamento adotado foi o inteiramente casualizado, os dados foram submetidos à análise da variância, e as médias comparadas ao teste de Duncan. As plantas cultivadas no substrato Plant Max ${ }^{\circledR}$ apresentaram quatro vezes mais massa seca das raízes e da parte aérea aos 180 dias. O crescimento das plântulas em turfa e casca de arroz foi menor em todos os parâmetros analisados. A propagação de Luehea divaricata a partir de sementes é tecnicamente viável nos substratos Plant Max ${ }^{\circledR}$ e Mec Plant ${ }^{\circledR}$, os quais proporcionaram maior crescimento e qualidade às mudas.

Palavras-chave: sementes; mudas; crescimento; substrato.

\section{ABSTRACT}

The species Luehea divaricata Mart. \& Zucc., from the Malvaceae family, has its wood used mainly in the manufacturing of curved furniture. Due to the wood quality interest, it is observed, as main result, the species deforestation. The purpose of this study was evaluate the growth of Luehea divaricata seedlings coming from seeds in four substrates. Four seeds were put in the tested substracts: Plant Max ${ }^{\circledR}$, black peat (mineralized), carbonizated rice hulls and Mec Plant ${ }^{\circledR}$. After 25 days, the seedlings were transplanted inside each treatment and, after 50 days, the seedlings were pruned. It was used the completely randomized experimental, the data underwent the variety analysis, and the averages were compared to Duncan's Test. The following parameters were considered: the percentage of seeds germination, dry weights of the root $(\mathrm{g})$, dry weights of the stem $(\mathrm{g})$, the stem diameter $(\mathrm{cm})$, the height of stem $(\mathrm{cm})$ and number of leaves. The cultivated plants in the Plant Max ${ }^{\circledR}$ substract showed four times more root dry mass and aerial part on the $180^{\text {th }}$ day. Black peat and carbonizated rice hulls were less effective in the growing of the seedlings in the all analyzed parameters. The propagation of Luehea divaricata from seeds is technically viable, it is one alternative for seedlings production of the species and the substract Plant Max $^{\circledR}$ and Mec Plant ${ }^{\circledR}$ was the best growth.

Keywords: seeds; seedlings; growth; substract.

\section{INTRODUÇÃO}

Os recursos florestais têm sido explorados através do desmatamento para suprir as diferentes necessidades de matéria-prima. Essa exploração ocasiona, posteriormente, a utilização das áreas para fins agropecuários. As sementes são o ponto de partida na produção de mudas que formarão plantios florestais, em pequena ou grande escala. Em casos extremos, podem ser a única solução para reverter o quadro de

1. Bióloga, MSc., Centro de Educação Superior Norte do Rio Grande do Sul (CESNORS), Campus de Frederico Westphalen, CEP 98.400-000, Frederico Westphalen (RS). fernandagrave@yahoo.com.br

2. Bióloga, Dra., Professora Associada da Universidade do Noroeste do Estado do Rio Grande do Sul (UNIJUÍ). Rua São Francisco, 501, Bairro São Geraldo, CEP 98700-000, Ijuí (RS). elcifranco@smail.ufsm.br

3. Biólogo, Mestrando pelo Programa de Pós-Graduação em Engenharia Florestal, Centro de Ciências Rurais, Universidade Federal de Santa Maria, Av. Roraima, 1000, Campus, CEP 97.105-900, Santa Maria (RS).

Recebido para publicação em 20/10/2005 e aceito em 29/08/2007. 
escassez de matéria-prima e de degradação ambiental (SENA e GARIGLIO, 1998).

O substrato apresenta papel importante no crescimento da planta em cultivos sem solo, tendo que garantir por meio de sua fase sólida o crescimento da parte aérea e o desenvolvimento do sistema radicular, com volume restrito. Exerce também as funções de dar sustentação às plantas, proporcionar o crescimento das raízes e fornecer as quantidades adequadas de ar, água e nutrientes (LEMAIRE, 1995). Além disso, deve apresentar uma estrutura que não dificulte a sua retirada do recipiente, por ocasião do plantio das mudas, e que não se destorroe, propiciando boas condições para o adequado desenvolvimento das plantas (STURION e ANTUNES, 2000).

A espécie Luehea divaricata, conhecida popularmente como açoita-cavalo, açoita-cavalo-miúdo, ibatingui, ivatingui, pau-de-canga, caiboti (LORENZI, 1998), pertence à família Malvaceae e é uma árvore que tem sua madeira empregada principalmente na confecção de móveis vergados (LORENZI, 1998; CARVALHO, 1994) por apresentar fácil trabalhabilidade, o que proporciona bom acabamento (CARVALHO, 1994). Possui também características ornamentais que a recomendam para o paisagismo, sendo considerada por Lorenzi (1998) como uma espécie pioneira de rápido crescimento, que não pode faltar nos reflorestamentos mistos de áreas degradadas de preservação permanente.

As sementes de Luehea divaricata, quanto ao armazenamento, são classificadas como ortodoxas e podem ser secas a teores de umidade abaixo de 5\% (base seca) e armazenadas a baixas temperaturas, por longos períodos, ocorrendo a redução da atividade metabólica. A maioria das espécies com frutos secos deiscentes e indeiscentes se enquadra nesta categoria (FOWLER, 2000). Apresentam dormência exógena atribuída à impermeabilidade do tegumento ou à presença de substâncias inibidoras.

A propagação da Luehea divaricata por sementes, segundo Reitz (1983), pode ser feita cobrindo tais sementes com uma fina camada de 1-2 cm de terra solta e úmida. Em viveiros, deve-se diminuir a luz direta e intensa do sol, bem como minimizar o impacto das gotas de chuva. Segundo Paoli (1995), a germinação ocorre de 8 a 15 dias, com o rompimento dos tegumentos e a protusão da radícula, e a emergência de novas plântulas ocorre no período de 20 a 40 dias após a semeadura (LORENZI, 1998).

Diante do atual cenário florestal, toda tecnologia que facilita ou viabiliza ecologicamente e comercialmente a produção de espécies nativas é atrativa. $\mathrm{O}$ crescente interesse por espécies nativas em programas de reflorestamento e na indústria madeireira, assim como a escassez de estudos sobre crescimento de plântulas visando maior produtividade e qualidade das mudas em condições de viveiro, são aspectos que incentivaram o desenvolvimento deste trabalho, que teve como objetivo verificar a influência de quatro diferentes substratos na germinação e no crescimento das plântulas de Luehea divaricata até 6 meses de idade.

\section{MATERIAIS E MÉTODOS}

O experimento foi realizado em casa de vegetação situada no Viveiro Florestal do Departamento de Ciências Florestais, e as avaliações foram realizadas no Laboratório de Fisiologia Vegetal do Departamento de Biologia da UFSM, Santa Maria - RS.

O material vegetal utilizado foram sementes de Luehea divaricata de várias árvores, coletadas no ano de 2003, beneficiadas e armazenadas em câmara fria do Laboratório de Sementes do Departamento de Ciências Florestais da UFSM.

Como pré-tratamento, as sementes permaneceram imersas em água por 24 horas, período que antecedeu a semeadura (FOWLER, 2000). Em dezembro de 2003, tubetes com capacidade de $126 \mathrm{~cm}^{3}$ foram preenchidos com os quatro substratos testados - Plant Max ${ }^{\circledR}$, turfa, casca de arroz carbonizada e Mec Plant ${ }^{\mathbb{B}}{ }^{\text {-, }}$, tomando-se cuidado para não haver a compactação dos mesmos nos recipientes. A seguir, foram colocadas quatro sementes por tubete em todos os substratos, as quais foram cobertas com uma fina camada de aproximadamente $5 \mathrm{~mm}$ do respectivo substrato, regadas com o auxílio de um regador plástico e acomodadas na casa de vegetação. Após 25 dias à semeadura, efetuou-se a repicagem das plântulas emergentes dentro de cada tratamento, objetivando a homogeneização, permanecendo apenas uma plântula por tubete. Aos 50 dias, após a fase de crescimento, foi realizado o desbaste ou raleio com o auxílio de uma tesoura, e foram descartadas as plântulas menores, permanecendo a mais robusta e central no tubete. A partir deste momento, as plântulas passaram para a etapa de rustificação, sendo retiradas da casa de vegetação e colocadas sob 
sombrite $50 \%$ em uma área situada no Viveiro Florestal. Durante todo o período, as plantas foram irrigadas diariamente, sendo que, em dias mais quentes, receberam mais de uma rega diária.

O delineamento experimental utilizado foi o inteiramente casualizado com 4 tratamentos - Plant $\mathrm{Max}^{\circledR}$, turfa, casca de arroz carbonizada e Mec Plant ${ }^{\circledR}$-, sendo que cada tratamento apresentou 3 repetições, e estas foram formadas por 20 plantas, totalizando 240 plantas (uma por tubete) em todo o experimento. Os dados foram submetidos à análise de variância, e as médias, comparadas pelo Teste de Duncan com $\alpha=0,01$.

Aos 60, 120 e 180 dias, avaliou-se o crescimento das plântulas a partir das variáveis percentagem de germinação das sementes, massa seca das raízes $(\mathrm{g})$, massa seca da parte aérea $(\mathrm{g})$, diâmetro do colo $(\mathrm{cm})$, altura da parte aérea $(\mathrm{cm})$ e número médio de folhas.

\section{RESULTADOS E DISCUSSÃO}

A germinação das sementes de Luehea divaricata ocorreu em todos os substratos (Plant Max ${ }^{\circledR}$, turfa, casca de arroz carbonizada e Mec Plant ${ }^{\mathbb{B}}$ ), cujos resultados podem ser observados na Tabela 1. Testes de germinação 'in vitro' realizados com esta espécie por Grave et al. (2004) indicavam o alto percentual germinativo das sementes (até 80\%), em meio de cultivo ágar-água. Resultados similares foram obtidos para a germinação nos diferentes substratos, fato este que reflete a adequação da disponibilidade de água dos mesmos para esta fase associados à boa qualidade do lote de sementes.

TABELA 1: Percentagem de germinação das sementes de Luehea divaricata nos quatro substratos testados (Plant Max ${ }^{\circledR}$, turfa, casca de arroz carbonizada, Mec Plant ${ }^{\circledR}$ ) aos 50 dias após a semeadura.

TABLE 1: Percentage of seeds germination of Luehea divaricata in the four tested substracts (Plant Max ${ }^{\circledR}$, black peat, carbonizated rice hulls and Mec Plant $\left.{ }^{\mathbb{B}}\right)$ at the $50^{\text {th }}$ day after the sowing.

\begin{tabular}{lc}
\hline Substrato & Percentagem de germinação das sementes \\
\hline Plant Max ${ }^{\circledR}$ & 91,2 \\
Turfa & 86,6 \\
Casca de arroz carbonizada & 90,0 \\
Mec Plant & 85,4 \\
\hline
\end{tabular}

Os resultados da massa seca das raízes encontram-se na Figura 1, na qual pode-se observar que as plântulas cultivadas no substrato Plant Max ${ }^{\circledR}$ obtiveram a maior massa seca das raízes, $1,1 \mathrm{~g}$ aos 180 dias $\left(3^{\mathrm{a}}\right.$ avaliação). Na $1^{\text {a }}$ avaliação (60 dias), as plântulas cujas sementes germinaram no substrato Plant Max ${ }^{\circledR}$, atingiram pouco mais de $0,15 \mathrm{~g}$ de massa seca das raízes, valores semelhantes aos alcançados na $3^{\mathrm{a}}$ avaliação (180 dias) nos substratos turfa e casca de arroz. Tais resultados comprovam que o substrato exerce grande influência na formação e arquitetura do sistema radicular, é de grande importância à porosidade do substrato para a aeração e aderência às raízes (HOFFMANN et al., 2001) e que apresenta sempre um espaço para permitir o desenvolvimento das raízes (BORDÁS et al., 1988), além da disponibilidade de água. Plant Max ${ }^{\circledR}$ é um produto comercial, e o melhor desempenho do crescimento do sistema radicular neste substrato foi provavelmente devido às suas características químicas e físicas, que proporcionaram o equilíbrio entre os teores de água, ar e a adequada densidade do substrato. Hoffmann et al. (2001) comprovaram a superioridade deste substrato quanto ao desenvolvimento do sistema radicular em macieira.

A massa seca das raízes das plântulas de Luehea divaricata, obtida no substrato casca de arroz carbonizada e turfa, foi reduzida, não apresentando diferença significativa nas três avaliações realizadas nos substratos testados (Figura 1). Isto evidencia que o desenvolvimento do sistema radicular nestes dois substratos foi lento até a $3^{\mathrm{a}}$ avaliação, o que poderá dificultar o desenvolvimento das plantas após o plantio. Já em grama-esmeralda (Zoysia japonica Steud.), o substrato contendo uma parte de casca de arroz carbonizada e outra parte de vermiculita apresentou resultados superiores nos demais parâmetros, destacando-se as características, tais como massa fresca da parte aérea e do sistema radicular, massa seca do sistema radicular e volume do sistema radicular (SALVADOR e MINAMI, 2002). 




FIGURA 1: Massa seca das raízes (g) das plântulas de Luehea divaricata aos 60,120 e 180 dias $\left(1^{\mathrm{a}}, 2^{\mathrm{a}}, 3^{\mathrm{a}}\right.$ avaliações), nos 4 diferentes substratos (Plant Max ${ }^{\circledR}$, turfa, casca de arroz carbonizada, Mec Plant ${ }^{\mathbb{B}}$ ). Médias seguidas de uma mesma letra minúscula dentro de cada substrato e de uma mesma letra maiúscula dentro de cada avaliação não diferem entre si pelo teste de Duncan com $\alpha=0,01$.

FIGURE 1: Root dry mass (g) of seedlings of Luehea divaricata at the $60^{\text {th }}, 120^{\text {th }}$ and $180^{\text {th }}$ days $\left(1^{\text {st }}, 2^{\text {nd }}, 3^{\text {rd }}\right.$ evoluations) in the four different substracts (Plant Max ${ }^{\circledR}$, black peat, carbonizated rice hulls, and Mec Plant ${ }^{\circledR}$ ). Averages followed by the same lower case inside each substract and by capital letter inside each evaluation don't differ among themselves by Duncan's Test with $\alpha=0,01$.

Na Figura 2, pode-se observar que ocorreu uma diferença significativa nos valores de massa seca da parte aérea entre os substratos testados nas três avaliações realizadas. As plântulas de Luehea divaricata cultivadas no substrato Plant Max $^{\circledR}$ obtiveram altos valores da massa seca da parte aérea, superiores aos demais substratos. Na $3^{\text {a }}$ avaliação (180 dias), as plântulas cultivadas no substrato comercial Plant Max ${ }^{\circledR}$ obtiveram $1,7 \mathrm{~g}$ de massa seca da parte aérea, enquanto as plântulas do substrato Mec Plant ${ }^{\circledR}$, o $2^{\circ}$ melhor desempenho, apresentaram $0,4 \mathrm{~g}$ de massa seca da parte aérea.

Cabe salientar que houve uma tendência de as plântulas com menor desenvolvimento do sistema aéreo apresentarem também menor desenvolvimento do sistema radicular nos substratos testados. Observando esses valores obtidos para os respectivos parâmetros avaliados, intensifica-se a hipótese de que a presença de folhas influencia diretamente no processo de enraizamento da espécie. Isto concorda com os resultados obtidos por Dutra e Kersten (1996), em estudos com estacas de ameixeira, nos quais os substratos que promoveram a maior queda de folhas apresentaram os menores percentuais de enraizamento. Já no cultivo de samambaia-matogrossense, observou-se visualmente que as plantas produzidas nos tratamentos que continham grandes quantidades do substrato Plant $\operatorname{Max}^{\circledR}$ apresentavam pequeno porte, folhas pequenas e em menor número, aspecto rústico e coloração clara, não sendo recomendado o seu uso, pois não produziram plantas de valor comercial (SALVADOR et al., 2001). Isto comprova mais uma vez que o substrato apresenta grande influência na espécie a ser propagada, ocorrendo respostas diferenciadas para cada uma delas, independente da quantidade de substrato utilizado. 


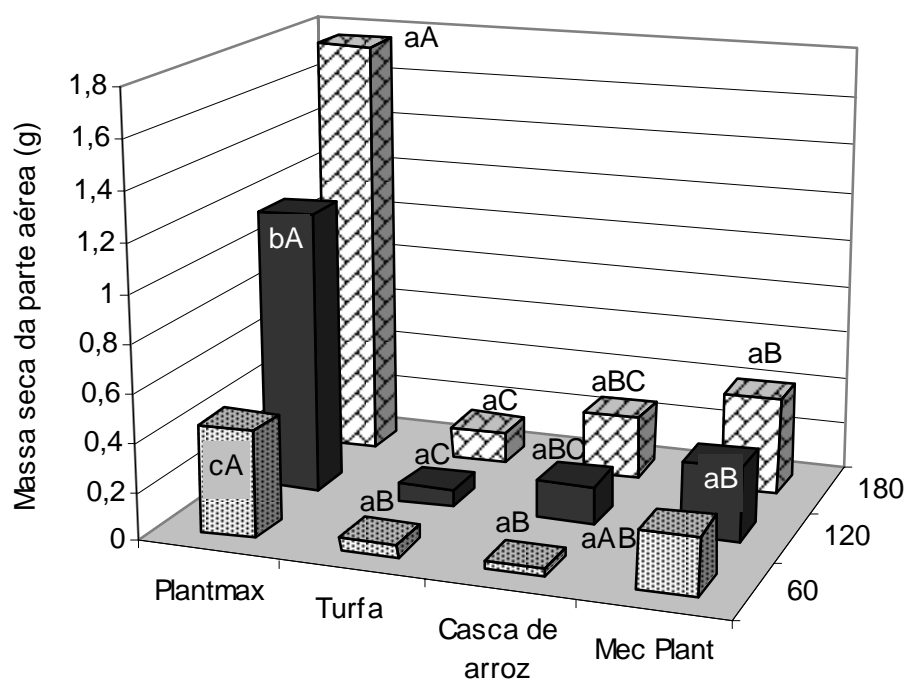

FIGURA 2: Massa seca da parte aérea (g) das plântulas de Luehea divaricata aos 60, 120 e 180 dias (1a $2^{\mathrm{a}}$, $3^{\mathrm{a}}$ avaliações) nos 4 diferentes substratos (Plant Max ${ }^{\circledR}$, turfa, casca de arroz carbonizada, Mec Plant ${ }^{\mathbb{B}}$ ). Médias seguidas de uma mesma letra minúscula dentro de cada substrato e de uma mesma letra maiúscula dentro de cada avaliação não diferem entre si pelo teste de Duncan com $\alpha=0,01$.

FIGURE 2: Dry mass from the aerial port $(\mathrm{g})$ of seedlings of Luehea divaricata at the $60^{\text {th }}, 120^{\text {th }}$ and $180^{\text {th }}$ days $\left(1^{\text {st }}, 2^{\text {nd }}, 3^{\text {rd }}\right.$ evaluats) in the four different substracts (Plant Max ${ }^{\circledR}$, black peat, carbonizated rice hulls and Mec Plant ${ }^{\mathbb{R}}$ ). Averages followed by the same lower case inside each substract and by capital letter inside each evaluation don't differ among themselves by Duncan's Test with $\alpha=$ 0,01 .

Ocorreu um progressivo aumento do diâmetro do colo das plântulas de Luehea divaricata até a última $\left(3^{\mathrm{a}}\right)$ avaliação em todos os substratos, conforme pode ser observado na Figura 3. As plantas cultivadas no Plant Max ${ }^{\circledR}$ triplicaram o diâmetro do colo ao final do período avaliado, o que demonstra ser o substrato adequado à produção de plântulas dessa espécie. Conforme Sturion e Antunes (2000), este parâmetro tem sido reconhecido como um dos melhores, senão o melhor, dos indicadores de padrão de qualidade. As mudas de pequeno diâmetro e muito altas são consideradas de qualidade inferior às menores, quando comparadas com aquelas de maior diâmetro de colo. Um maior diâmetro de colo está associado a um desenvolvimento mais acentuado da parte aérea e, em especial, do sistema radical, favorecendo a sobrevivência e o desenvolvimento da muda após o plantio. Scalon et al. (2002) observou, no crescimento inicial de mudas de espécies florestais nativas, a importância do diâmetro do colo como característica valiosa na avaliação do potencial da muda para a sobrevivência e o crescimento após o plantio. De acordo com Carneiro (1983) apud Scalon (2002), as plantas com maior diâmetro apresentam percentual de sobrevivência mais elevado, principalmente pela maior capacidade de formação e de crescimento de novas raízes. 


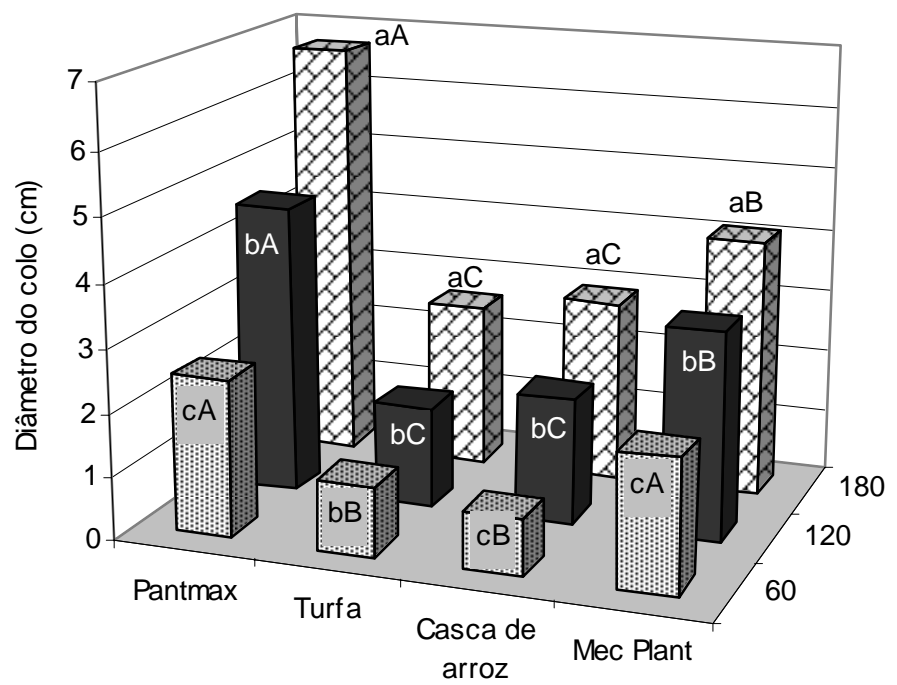

FIGURA 3: Diâmetro do colo $(\mathrm{cm})$ das plântulas de Luehea divaricata aos 60,120 e 180 dias $\left(1^{\mathrm{a}}, 2^{\mathrm{a}}, 3^{\mathrm{a}}\right.$ avaliações) nos 4 diferentes substratos (Plant Max ${ }^{\circledR}$, turfa, casca de arroz carbonizada, Mec Plant $\left.{ }^{\mathbb{B}}\right)$. Médias seguidas de uma mesma letra minúscula dentro de cada substrato e de uma mesma letra maiúscula dentro de cada avaliação não diferem entre si pelo teste de Duncan com $\alpha=0,01$.

FIGURE 3: Stem diameter $(\mathrm{cm})$ of seedlings of Luehea divaricata at the $60^{\text {th }}, 120^{\text {th }}$ and $180^{\text {th }}$ days $\left(1^{\text {st }}, 2^{\text {nd }}, 3^{\text {rd }}\right.$ evaluats) in the four different substracts (Plant Max ${ }^{\circledR}$, black peat, carbonizated rice hulls and Mec Plant $\left.^{\circledR}\right)$. Averages followed by the same lower case inside each substract and by capital letter inside each evaluation don't differ among themselves by Duncan's Test with $\alpha=0,01$.

Na Figura 4, estão representados os resultados obtidos no parâmetro altura média da parte aérea. Constata-se que não ocorreu diferença significativa dentro de cada tratamento (substrato) entre a $2^{\mathrm{a}}$ e $3^{\mathrm{a}}$ avaliação (120 e 180 dias respectivamente). Em todos os substratos testados, o sistema aéreo estava bem desenvolvido aos 120 dias, principalmente no substrato Plant Max ${ }^{\circledR}$, que apresentou altura média da parte aérea em torno de $26 \mathrm{~cm}$. O fato de a altura média da parte aérea não apresentar diferença significativa entre a $2^{\mathrm{a}}$ e $3^{\mathrm{a}}$ avaliação pode ser explicado pela restrição do desenvolvimento do sistema radicular, imposta pelo volume do recipiente (tubete), refletindo no desenvolvimento da parte aérea, como pode ser visto na Figura 6. Em mudas de angico e sesbânia, estudadas por Samôr et al. (2002), parâmetros, como altura, área foliar e produção de biomassa das plantas, apresentaram valores reduzidos devido à restrição do crescimento do sistema radicular determinado pelos tamanhos dos recipientes. 


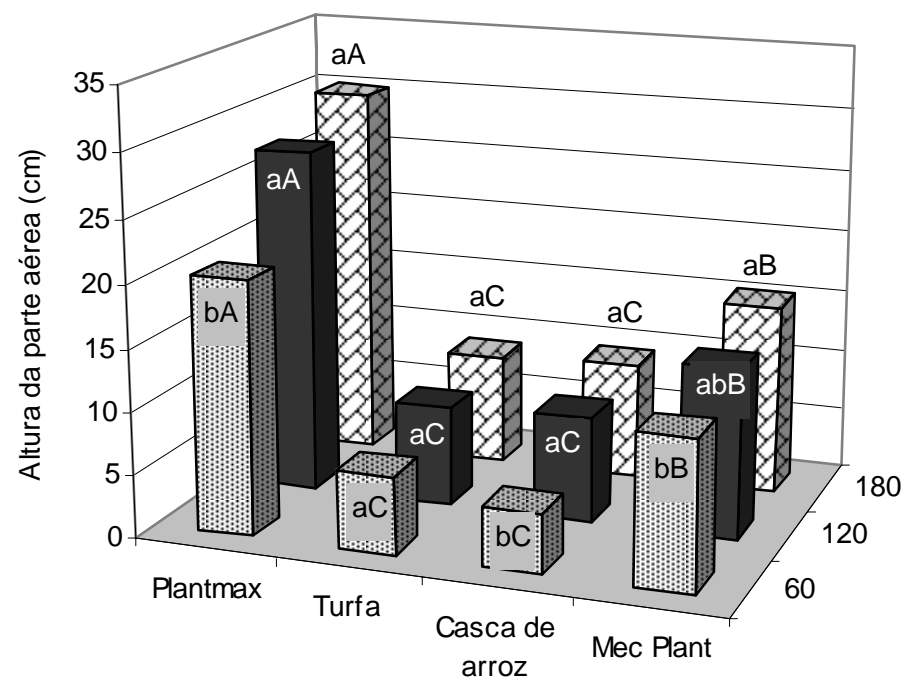

FIGURA 4: Altura média da parte aérea $(\mathrm{cm})$ das plântulas de Luehea divaricata aos 60, 120 e 180 dias $\left(1^{\mathrm{a}}\right.$, $2^{\mathrm{a}}, 3^{\mathrm{a}}$ avaliações) nos 4 diferentes substratos (Plant Max ${ }^{\circledR}$, turfa, casca de arroz carbonizada, Mec Plant ${ }^{\circledR}$ ). Médias seguidas de uma mesma letra minúscula dentro de cada substrato e de uma mesma letra maiúscula dentro de cada avaliação não diferem entre si pelo teste de Duncan com $\alpha=0,01$.

FIGURE 4: Aerial part height $(\mathrm{cm})$ of seedlings of Luehea divaricata at the $60^{\text {th }}, 120^{\text {th }}$ and $180^{\text {th }}$ days $\left(1^{\text {st }}, 2^{\text {nd }}\right.$, $3^{\text {rd }}$ evaluats) in the four different substracts (Plant Max ${ }^{\circledR}$, black peat, carbonizated rice hulls and Mec Plant $\left.{ }^{\circledR}\right)$. Averages followed by the same lower case inside each substract and by capital letter inside each evaluation don't differ among themselves by Duncan's Test with $\alpha=0,01$.

Em relação ao número médio de folhas das plântulas cultivadas nos quatro substratos testados, observa-se, nas Figuras 5 e 6, que: na $1^{a}$ avaliação (60 dias), não ocorreu diferença significativa deste parâmetro das plântulas cultivadas nos substratos Plant Max $^{\circledR}$ e casca de arroz carbonizada; na $3^{\text {a }}$ avaliação (180 dias), o número médio de folhas das plântulas provenientes dos substratos Plant $\operatorname{Max}^{\circledR}$ e $\operatorname{Mec}^{P}$ Plant ${ }^{\mathbb{B}}$ também não diferiram estatisticamente; porém, houve um menor número médio de folhas das plantas cultivadas no substrato de turfa e casca de arroz carbonizada, o que pode ser explicado devido à diferença de composição e disponibilidade de nutrientes de cada substrato. 


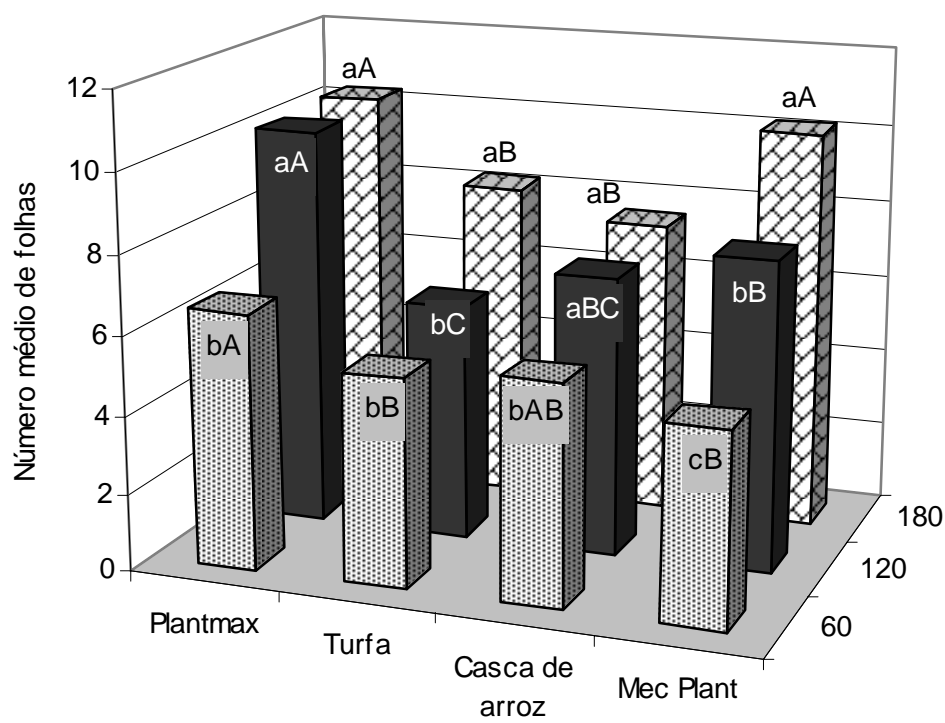

FIGURA 5: Número médio de folhas das plântulas de Luehea divaricata aos 60,120 e 180 dias $\left(1^{\mathrm{a}}, 2^{\mathrm{a}}, 3^{\mathrm{a}}\right.$ avaliações) nos 4 diferentes substratos (Plant Max ${ }^{\circledR}$, turfa, casca de arroz carbonizada, Mec Plant ${ }^{\mathbb{B}}$. Médias seguidas de uma mesma letra minúscula dentro de cada substrato e de uma mesma letra maiúscula dentro de cada avaliação não diferem entre si pelo teste de Duncan com $\alpha=0,01$.

FIGURE 5: Height of leaves of seedlings of Luehea divaricata at the $60^{\text {th }}, 120^{\text {th }}$ and $180^{\text {th }}$ days $\left(1^{\text {st }}, 2^{\text {nd }}, 3^{\text {rd }}\right.$ evaluats) in the 4 different substracts (Plant Max ${ }^{\circledR}$, black peat, carbonizated rice hulls and Mec Plant $\left.{ }^{\mathbb{B}}\right)$. Averages followed by the same lower case inside each substract and by capital letter inside each evaluation don't differ among themselves by Duncan's Test with $\alpha=0,01$.

Cunha et al. (2002), estudando o cafeeiro, obtiveram os melhores resultados na variável número médio de folhas com plantas advindas do substrato Plant Max ${ }^{\circledR}$, o que comprova a sua funcionalidade neste parâmetro. Destacam-se a importância da emissão de folhas e, conseqüentemente, o aumento da taxa fotossintética, fornecendo a energia necessária para o crescimento e o desenvolvimento da nova plântula, principalmente quando a área foliar é maior, como podemos observar na Figura 6.

As plântulas de Luehea divaricata, cultivadas nos substratos casca de arroz carbonizada e turfa, apresentaram resultados inferiores em todos os parâmetros analisados comparativamente aos substratos Plant Max $^{\circledR}$ e Mec Plant ${ }^{\circledR}$, como pode ser observado na Figura 6. Esse crescimento inferior está relacionado com as características do substrato, como menor suscetibilidade às limitações de temperatura, disponibilidade e água, ar e outras características físico-químicas. 



FIGURA 6: Plântulas de Luehea divaricata cultivadas nos substratos turfa (T), casca de arroz carbonizada (C), Plantmax $^{\circledR}(\mathrm{P})$ e Mec Plant ${ }^{\mathbb{B}}(\mathrm{M})$ : (A) aos 60 dias após a semeadura, (B) aos 120 dias, (C) aos 180 dias.

FIGURE 6: (A) Seedlings of Luehea divaricata cultivated in black peat (T) and carbonizated rice hulls (C), $\operatorname{PlantMax}^{\circledR}(\mathrm{P})$ and Mec Plant ${ }^{\mathbb{B}}(\mathrm{M})$ : $(\mathrm{A})$ at the $60^{\text {th }}$ day after the sowing, (B) at the $120^{\text {th }}$ day and (C) at the $180^{\text {th }}$ day.

O desenvolvimento semelhante das plântulas cultivadas nos substratos Plant Max $^{\circledR}$ e Mec Plant ${ }^{\circledR}$ (Figura 6) podem ser atribuídos às boas condições físicas proporcionadas por estes substratos, principalmente pela disponibilidade de água e nutrientes na fase líquida, pelo oxigênio e mais o transporte do dióxido de carbono na fase gasosa (LEMAIRE, 1995), pela densidade adequada, além das características químicas, como $\mathrm{pH}$, teor de sais solúveis e capacidade de troca de cátions. Plant Max ${ }^{\circledR}$ e Mec Plant ${ }^{\circledR}$ apresentam vantagem em relação aos outros substratos, principalmente aos que apresentam materiais orgânicos como componentes, pela uniformidade de composição química e física, sendo esse aspecto de grande importância em trabalhos de pesquisa e também na produção comercial de plantas. Desta forma, assegura-se a replicabillidade dos resultados devido a sua formulação comercial, que deve ser exata. Os resultados obtidos neste estudo, com a produção de plantas de Luehea divaricata mais desenvolvidas e de alto vigor, comprovam a importância do substrato na produção de mudas de qualidade.

\section{CONCLUSÃO}

Os resultados obtidos permitem concluir, para Luehea divaricata, que:

A germinação ocorreu em todos os substratos.

O tipo de substrato influencia no desenvolvimento das plântulas, até 180 dias de idade.

A produção de plântulas de melhor qualidade foi obtida nos substratos comerciais Plant $\operatorname{Max}^{\circledR}$ e Mec Plant ${ }^{\circledR}$, enquanto que, na turfa e casca de arroz carbonizada, o crescimento e o desenvolvimento das plântulas foram menores.

Sugerem-se estudos futuros da transferência das plântulas dos tubetes para um local definitivo.

\section{AGRADECIMENTOS}

À CAPES, pela bolsa concedida.

\section{REFERÊNCIAS BIBLIOGRÁFICAS}

BORDÁS, J.M.C.; BACKES, M.A.; KÄMPF, A.N. Características físicas e químicas dos substratos comerciais. In: CONGRESSO FLORESTAL ESTADUAL, 6., 1988, Nova Prata. Anais... Nova Prata: Prefeitura Municipal, 1988. p.427-435.

CARVALHO, P. E. R. Espécies florestais brasileiras : recomendações silviculturais, potencialidades e uso da madeira. Brasília : EMBRAPA-CNPF/SPI, 1994.

CUNHA, R.L.; SOUZA, C.A.S.; NETO, A.A. et al. Avaliação de substratos e tamanhos de recipientes na formação de 
mudas de cafeeiros (Coffea arabica L.) em tubetes. Ciência Agrotécnica, v.26, n.1, p.7-12, 2002.

DUTRA, L.F.; KERSTEN, E. Efeito do substrato e da época de coleta dos ramos no enraizamento de estacas de ameixeira (Prunus salicina Lindl.). Ciência Rural, v.26, n.3, p.361-366, 1996.

FOWLER, J.A.P. Superação de dormência e armazenamento de sementes de espécies florestais. In: GALVÃO, A.P.M. (Ed.). Reflorestamento de propriedades rurais para fins produtivos e ambientais. Brasília: EMBRAPA, 2000. p.77-100.

GRAVE, F.; FRANCO, E.T.H.; PACHECO, J. P. et al. Germinação das sementes de açoita-cavalo (Luehea divaricata Martius). In: ENCONTRO ESTADUAL DE BOTÂNICA, SOCIEDADE DE BOTANICA DO BRASIL, 12. , 2004. Anais... Canoas : ULBRA, 2004, Canoas. 1 CD-ROM.

HOFFMANN, A.; PASQUAL, M.; CHALFUN, N.N.J. et al. Efeito dos substratos na aclimatização de plantas micropropagadas do porta-enxerto de macieira 'marubakaido'. Ciência Agrotécnica, v.25, n.2, p.462-467, 2001.

LEMAIRE, F. Physical, chemical, and biological properties of growing medium. Acta Horticulturae, n. 396, p.273284, 1995 .

LORENZI, H. Árvores brasileiras: manual de identificação de plantas arbóreas nativas do Brasil. 2. ed. São Paulo: Editora Plantarum, v.1, 1998. p.388.

PAOLI, A.A.S. Morfologia e desenvolvimento de sementes e plântulas de Luehea divaricata Mart. \& Zucc. (Tiliaceae). Revista Brasileira de Sementes, v.17, n.1, p.120-128, 1995.

REITZ, R., KLEIN, R. M., REIS, A. Projeto Madeira do Rio Grande do Sul. Porto Alegre: Secretaria da Agricultura e Abastecimento, 1983. 524p.

SALVADOR, E.D.; MINAMI, K. Avaliação de diferentes substratos no cultivo de grama-esmeralda (Zoysia japonica Steud.) em bandejas. Ciência Agrotécnica, v.26, n.2, p.232-236, 2002.

SALVADOR, E.D.; PASQUAL, M.; SPERA, M.R.N. Efeito de diferentes substratos no crescimento de samabaiamatogrossense (Polypodium aureum L.). Ciência Agrotécnica, v.25, n.4, p.1006-1111, 2001.

SAMÔR, O.J.M.; CARNEIRO, J.G.A.; BARROSO, D.G. et al. Qualidade de mudas de angico e sesbânia, produzidas em diferentes recipientes e substratos. Revista Árvore, v.26, n.2, p.209-215, 2002.

SCALON, S.P.U; MUSSURY R.M.; RIGONI, M.R. et al. Crescimento inicial de mudas de espécies florestais nativas sob diferentes níveis de sombreamento. Revista Árvore, v.26, n.1, p.1-5, 2002.

SENA, C.M., GARIGLIO, M.A. Sementes florestais: colheita, beneficiamento e armazenamento. Natal: [s.n.], 1998. $27 \mathrm{p}$.

STURION, J.A.; ANTUNES, J.B.M. Produção de mudas de espécies florestais. In: GALVÃO, A.P.M. Reflorestamento de propriedades rurais para fins produtivos e ambientais. Brasília : EMBRAPA, 2000. cap.7, p.125-150. 